\title{
A Carbon Nanotube-Metal Oxide Hybrid Material for Visible-Blind Flexible UV-Sensor
}

\author{
Pawan Pathak * (D), Sanghoon Park and Hyoung Jin Cho* \\ Department of Mechanical and Aerospace Engineering, University of Central Florida, Orlando, FL 32816, USA; \\ sanghoon.park@ucf.edu \\ * Correspondence: pawan.pathak@ucf.edu (P.P.); hjcho@ucf.edu (H.J.C.); Tel.: +1 407-823-5014 (H.J.C.)
}

Received: 6 February 2020; Accepted: 30 March 2020; Published: 1 April 2020

\begin{abstract}
Flexible sensors with low fabrication cost, high sensitivity, and good stability are essential for the development of smart devices for wearable electronics, soft robotics, and electronic skins. Herein, we report a nanocomposite material based on carbon nanotube and metal oxide semiconductor for ultraviolet (UV) sensing applications, and its sensing behavior. The sensors were prepared by a screen-printing process under a low-temperature curing condition. The formation of a conducting string node and a sensing node could enhance a UV sensing response, which could be attributed to the uniform mixing of functionalized multi-walled carbon nanotubes and zinc oxide nanoparticles. A fabricated device has shown a fast response time of $1.2 \mathrm{~s}$ and a high recovery time of $0.8 \mathrm{~s}$ with good mechanical stability.
\end{abstract}

Keywords: $\mathrm{ZnO}$; carbon nanotube (CNT); flexible sensor; photodetector

\section{Introduction}

The ozone layer has been depleted due to human activities, including the production of chlorofluorocarbon compounds, which has detrimentally disrupted the ecosystem resulting from the increased UV dose through the atmosphere [1,2]. The enhanced exposure to UV produces an adverse impact on human health and other living organisms [3]. Thus, UV sensors are important for monitoring UV radiation effectively and to avoid damage by excessive exposure. The UV sensors can also be used in other areas, for example, flame sensing, imaging, space communications, missile tracking, etc. [4-6]. It is imperative to monitor UV exposure levels in real time in order to prevent skin health-related risks such as inflammatory disorders, wrinkles, and skin cancer. The recent advancement of wearable electronics has generated a lot of attention and raised the demand for flexible sensors that can be integrated into existing technology. However, the commercially established UV sensors based on silicon technology are not suitable due to their mechanical rigidness and lack of UV selectiveness.

A nanomaterial-based metal oxide semiconductor has been recognized as an alternative to the silicon-based technology due to flexibility and the wide bandgap that can be exploited for UV sensing. Metal oxides can be assembled as a thin film on a wide range of substrates using a cost-effective wet chemical approach [7]. Among the various metal oxides, $\mathrm{ZnO}, \mathrm{CuO}$, and $\mathrm{TiO}_{2}$ are promising metal oxide semiconductors for their chemical stability, low toxicity, and high selectivity [8-10]. ZnO is one of the most widely studied oxide materials for UV sensing applications because of a high exciton binding energy of $60 \mathrm{meV}$ and a wide bandgap of $3.37 \mathrm{eV}$ [11,12]. However, pristine ZnO-based UV sensors have shown low sensitivity, which makes it unsuitable for the real-time measurement of UV radiation. Carbon is earth abundant, low cost material that can be introduced to a metal oxide semiconductor for an effective charge separation and transportation [13,14]. Various carbon allotropes such as fullerenes, carbon nanotubes, and graphene have been studied for nanoelectronics, optoelectronics, supercapacitors, and solar cell applications in the past few decades $[15,16]$. Several 
groups have studied the carbon nanotube metal oxide semiconductor network for UV sensing and gas sensing applications [17-20]. However, improvements in the performance of the device due to the incorporation of carbon allotropes is highly affected by its random aggregation [14]. Yi et al. have studied the influence of the presence of functional groups on the aggregation kinetics of the multiwalled carbon nanotube [21]. The result suggested that the oxidized carbon nanotube (carbonyl, carboxyl, and hydroxyl groups) is more stable to aggregation and deposition.

Scheme 1 presents the benefit of carbon nanotube in composite material. The presence of carbon nanotube can provide stable electrical connections between metal oxide semiconductors and planar interdigitated electrodes. Carbon nanotube collects and transmits free charge carriers without much loss, so the small change in the conductivity of metal oxide semiconductor particle could be reliably detected.

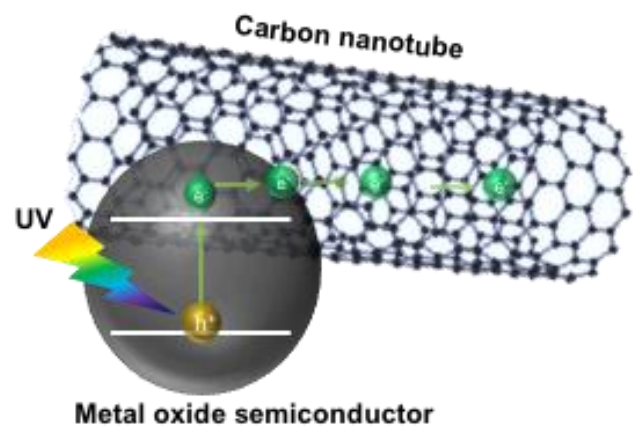

Scheme 1. Schematic representation of the working principle of the nanocomposite sensor.

In this work, we have introduced a hybrid nanomaterial for flexible, visible-blind UV sensors. Both the electrode and sensing material were fabricated using a screen-printing method on a flexible polyethylene terephthalate (PET) substrate. The mixture of $\mathrm{OH}$ functionalized multi-walled carbon nanotubes (MWCNTs) (OH-MWCNT) and ZnO nanoparticles of different ratios was optimized with respect to the UV sensing performance. Also, a sensing mechanism of the device was studied using various characterization tools. It was found that the use of nanocomposite sensing material enhanced UV sensing characteristics, i.e., repeatability, response times, and mechanical stability. This strategy could be used to fabricate low cost, flexible, and wearable UV sensors.

\section{Materials and Methods}

\subsection{Chemicals}

Zinc acetate, ammonia solution, terpinol, ethanol, and methanol were obtained from Sigma Aldrich (St. Louis, MO, USA). Ethylene cellulose, silver paste, and multiwalled OH-MWCNT were obtained from Alfa Assar (Ward Hill, MA, USA), Daejoo Electronic Materials (Gyeonggi-Do, Korea), and Cheap Tubes (Cambridgeport, VT, USA), respectively. All these chemicals were used without additional treatment or purification.

\section{2. $\mathrm{ZnO}$ Nanoparticle Synthesis}

The approach used for the synthesis of $\mathrm{ZnO}$ nanoparticle is described elsewhere [22]. Briefly, 0.6 $\mathrm{M}$ zinc acetate solution was prepared in methanol solvent. The solution was stirred at $80{ }^{\circ} \mathrm{C}$ for two hours for well mixing. The $\mathrm{pH}$ of the solution was adjusted between 9 to 11 using an ammonia solution, and the solution was dried at $100^{\circ} \mathrm{C}$. Later, the temperature of the solution was further increased to $150{ }^{\circ} \mathrm{C}$ for the gelation process. The prepared $\mathrm{ZnO}$ nanoparticles were washed and dried several times to remove impurities. Finally, the $\mathrm{ZnO}$ nanoparticles were annealed at $500{ }^{\circ} \mathrm{C}$ for 2 hours to improve crystallinity. 


\subsection{Preparation of $\mathrm{OH}-\mathrm{MWCNT/ZnO} \mathrm{Nanocomposite}$}

The composite was formed by mixing $\mathrm{ZnO}$ and OH-MWCNT. In order to avoid the known dispersion problem with carbon nanotubes in a solvent, $\mathrm{OH}$-functionalized MWCNTs were used to achieve uniform mixing and high interfacial bonding [23]. First, $2 \mathrm{~g}$ of ethylene cellulose was dissolved in $20 \mathrm{~mL}$ of ethanol and $78 \mathrm{~mL}$ of terpinol and stirred via a magnetic stirrer for $24 \mathrm{~h}$. Ethylene cellulose was used to enhance the bonding strength between the sensing material and the substrate. Then different concentrations of the OH-MWCNT and $\mathrm{ZnO}$ were added to the mixture in such a way that the weight ratio of the solvent to the solution was 60:40.

\subsection{Device Fabrication}

Figure 1 shows the device fabrication procedure. Metal mesh screens (NBC Meshtec Americas Inc., Batavia, IL, USA) were used for printing inks for conducting and sensing layers. A PET substrate was used as a low cost and flexible substrate. First, silver interdigitated electrodes were printed manually by squeezing silver paste through the metal mesh screen to the PET substrate. After printing, samples were dried at room temperature for $4 \mathrm{~h}$. Then, the OH-MWCNT/ZnO composite film was printed as a sensing layer on top of the planar interdigitated electrodes. The low-temperature treatment ensures that it would not thermally damage the PET substrate.

(a)

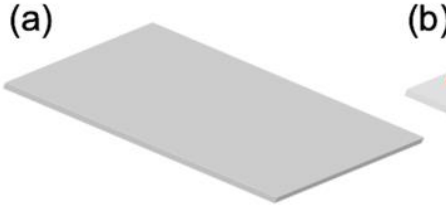

(b)

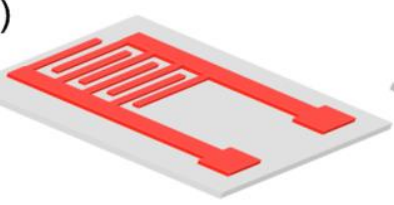

(c)

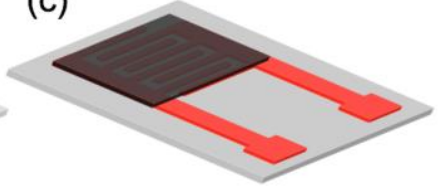

Figure 1. Schematic illustration of the fabrication of a flexible ultraviolet (UV) sensor; (a) polyethylene terephthalate (PET) substrate; (b) screen printed silver electrode; and (c) screen printed sensing layer.

\subsection{Materials Characterization}

Electrical characterizations were performed using Keithley 2401 (Tektronix Inc., Beaverton, OR, USA) at room temperature. Optical characterization of the materials was carried out using an Agilent Cary 300 spectrophotometer (Agilent Technologies Inc. Santa Clara, CA, USA) in the wavelength range of $250-550 \mathrm{~nm}$. The surface morphologies of the samples were probed using a Zeiss ultra 55 scanning electron microscope (SEM) system (Carl Zeiss SMT GmbH, Oberkochen, Germany) operated at $5 \mathrm{keV}$. The $365 \mathrm{~nm}$ centered laser was used as the laser source for UV sensing characterization. An X-ray photoelectron spectroscopy (XPS) were collected on ESCALAB ${ }^{\mathrm{TM}}$ XI+ X-ray Photoelectron Spectrometer Microprobe (Thermo Scientific, Waltham, MA, USA). Monochromatic, micro-focused Al $\mathrm{K} \alpha$ line was used to analyze the XPS of the sample.

\section{Results and Discussion}

\subsection{Morphology Analysis}

Figure 2 shows the SEM image of the morphology of the composite material. The image reveals the tube-like structure of the OH-MWCNT and particle-like structure of ZnO. The OH-MWCNT was used as the conducting string and $\mathrm{ZnO}$ was used as the sensing node. The average carbon nanotube diameter is $15 \mathrm{~nm}$ with few microns in length, and the size of the average nanoparticles is $80 \mathrm{~nm}$ in diameter. Elemental dispersive X-ray spectroscopy (EDX) analysis shows the elemental composition of the sensing layer. 

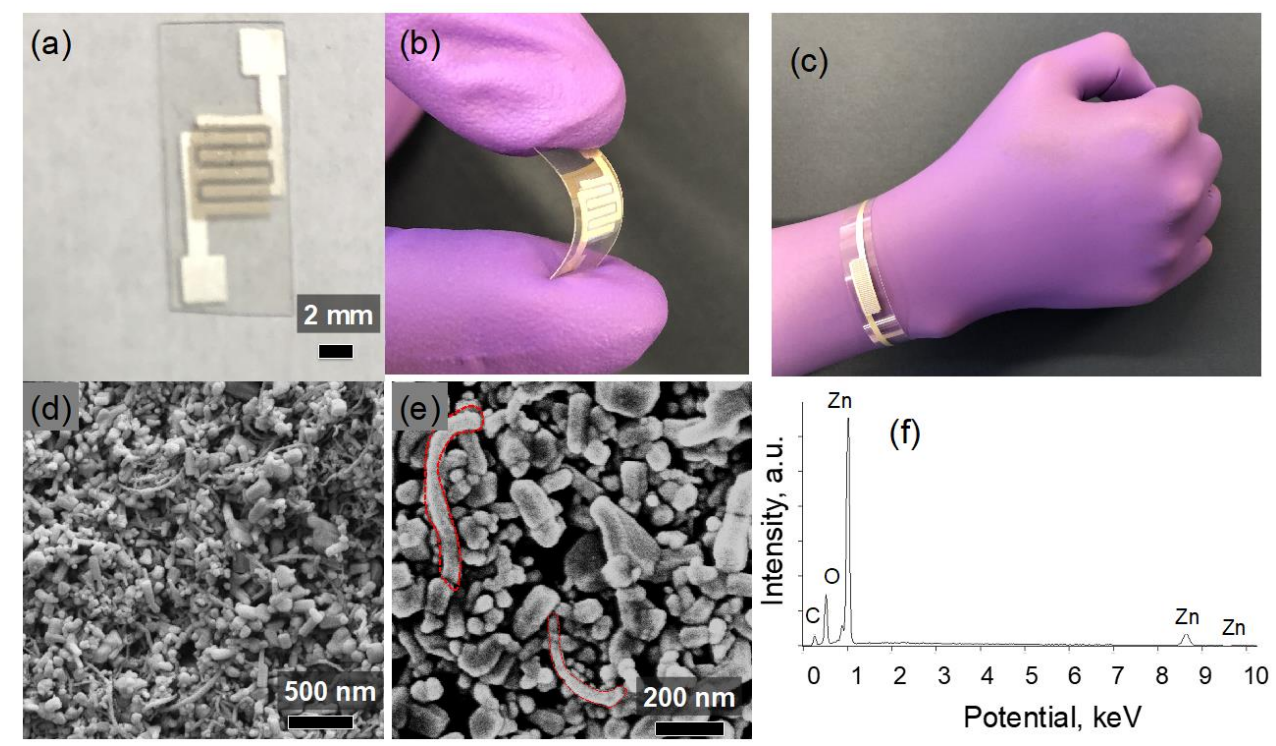

Figure 2. (a) Optical images of the fabricated sensor; $(\mathbf{b}, \mathbf{c})$ demonstrating the flexibility of the sensor; (d,e) scanning electron microscope (SEM) image of the sensing material at different magnification; and (f) elemental dispersive X-ray spectroscopy (EDX) of the sensing material showing the elemental composition.

The XPS spectra of $\mathrm{ZnO}$ and OH-MWCNT/ZnO is presented in Figure 3. The survey peak of the synthesized $\mathrm{ZnO}$ nanoparticles is shown in Figure $3 \mathrm{a}$ indicates the presence of zinc and oxygen. Figure $3 b, c$ shows the high-resolution XPS spectra of Zn 2p and O 1S, respectively. The two clear, distinct peaks located at 1021.3 and $1044.4 \mathrm{eV}$ are attributed to the spin-orbit of $\mathrm{Zn} 2 \mathrm{p}_{3 / 2}$ and $\mathrm{Zn} 2 \mathrm{p}_{1 / 2}$, respectively. The energy splitting between the $\mathrm{Zn} 2 \mathrm{p}_{1 / 2}$ and $\mathrm{Zn} 2 \mathrm{p}_{3 / 2}$ is $\sim 23.1 \mathrm{eV}$ is in agreement with the reported value [24]. The $\mathrm{O} 1 \mathrm{~s}$ core peak (Figure 3c) of $\mathrm{ZnO}$ nanoparticles shows one distinct peak at $529.8 \mathrm{eV}$ associated with $\mathrm{O}^{2-}$ ions in the $\mathrm{Zn}-\mathrm{O}$ bonding of the $\mathrm{ZnO}$ nanoparticle [24]. The survey peak of OH-MWCNT/ZnO composite is shown in Figure $3 \mathrm{~d}$ indicates the presence of zinc, oxygen, and carbon. The high-resolution XPS peaks of the $\mathrm{Zn}$ presented in Figure 3e reveals two binding energy peaks at 1021.3 and $1044.4 \mathrm{eV}$ associated with $\mathrm{Zn} 2 \mathrm{p}_{1 / 2}$ and $\mathrm{Zn} 2 \mathrm{p}_{3 / 2}$ spin-orbit splitting, respectively. The result indicates that there is no change in the chemical state of $\mathrm{Zn}$ in the OH-MWCNT/ZnO composite compared to that of $\mathrm{Zn}$ in the $\mathrm{ZnO}$ nanoparticle. However, the $\mathrm{O}$ 1s peak (Figure 3f) of $\mathrm{OH}-\mathrm{MWCNT} / \mathrm{ZnO}$ composite is resolved into two peaks centered at 529.8 and $532.0 \mathrm{eV}$, representing the $\mathrm{Zn}-\mathrm{O}$ bonding and $\mathrm{C}-\mathrm{O}$, respectively. The $\mathrm{C} 1$ s peak (Figure $3 \mathrm{~g}$ ) was fitted into three peaks centered at $584.7,585.4$, and $586.9 \mathrm{eV}$. The peak centered at $586.9 \mathrm{eV}$ is associated with $\mathrm{C}-\mathrm{O}$ groups in the form of $\mathrm{C}-\mathrm{OH}$ [25]. The $\mathrm{sp}^{2}$ and $\mathrm{sp}^{3}$ hybridized carbon peaks were observed at 284.7 and $285.4 \mathrm{eV}$ respectively [26]. The result suggests the formation of a composite material. 

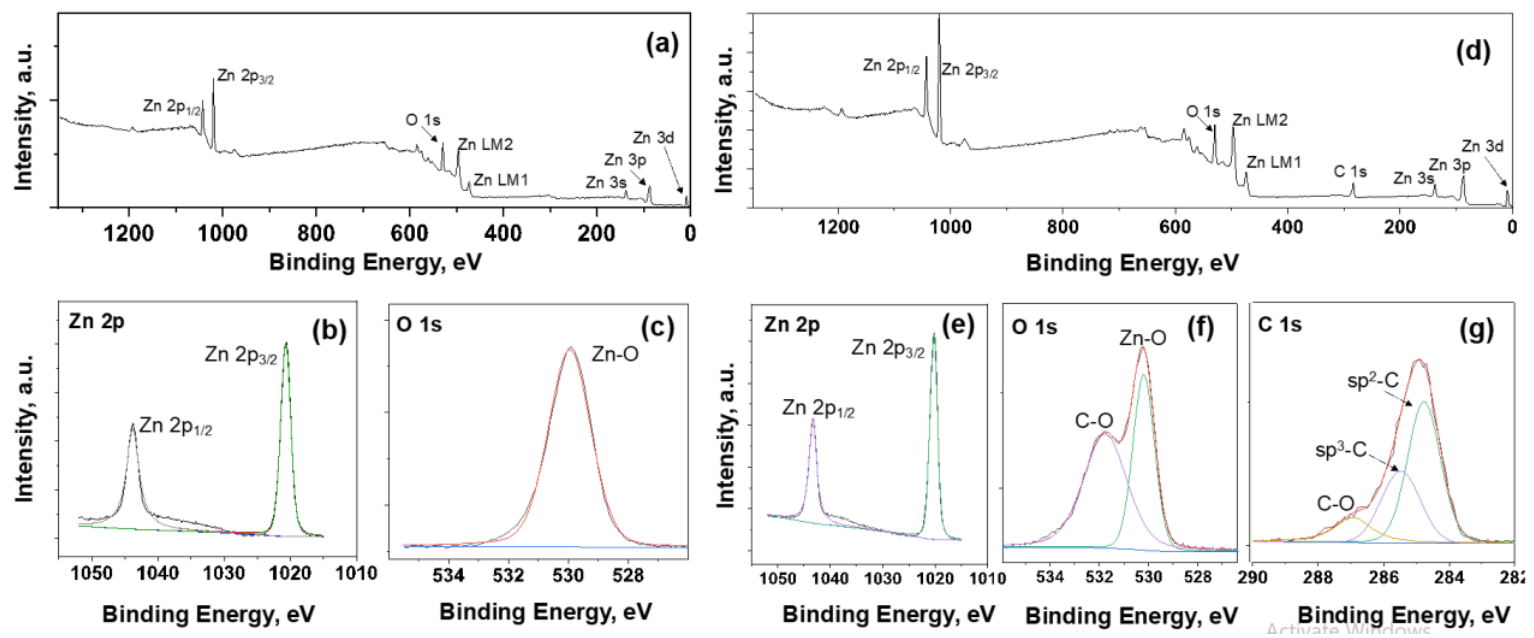

Figure 3. X-ray photoelectron spectroscopy (XPS) analysis of $\mathrm{ZnO}$ nanoparticles and $\mathrm{OH}$ functionalized multi-walled carbon nanotube (MWCNT)/ZnO composite. (a)Survey peak of $\mathrm{ZnO}$; (b) Zn 2p spectra of $\mathrm{ZnO}$; (c) O 1s spectra of $\mathrm{ZnO}$; (d) Survey peak of composite; (e) Zn 2p spectra of composite; (f) O 1s spectra of composite; and (g) C 1s spectra of composite

\subsection{Optical Absorbance of the Films}

Figure 4 shows the absorbance spectra of composite material on a PET substrate from $250 \mathrm{~nm}$ to $550 \mathrm{~nm}$. The absorption edge of the composite sensing material is $382 \mathrm{~nm}$. It shows that the composite material can absorb UV radiation selectively without the need of optical filters.

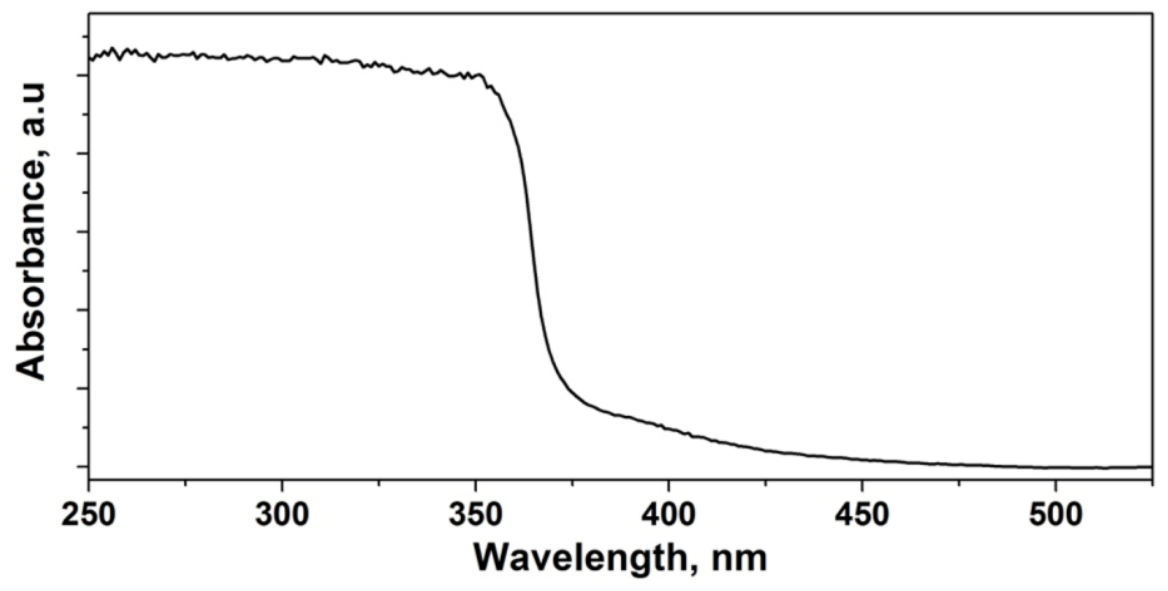

Figure 4. Room temperature optical absorbance spectra of the composite sensing material.

\subsection{Sensor Response}

The devices (composite (OH-MWCNT/ZnO) and $\mathrm{ZnO}$ alone) have shown distinct electrical responses to the UV radiation, as shown in Figure 5. The current time characteristics of a fabricated nanocomposite sensor under cyclic on-off illumination of $20 \mathrm{~mW} / \mathrm{cm}^{2} \mathrm{UV}$ radiation at applied bias in the range of $0.5 \mathrm{~V}$ to $2 \mathrm{~V}$ is presented in Figure $5 \mathrm{a}$. The response time and recovery time of the sensor calculated at $1.5 \mathrm{~V}$ bias current (Figure $5 \mathrm{a}$ ) are $1.2 \mathrm{~s}$ and $0.8 \mathrm{~s}$, respectively. The photocurrent increased with the increase in bias voltage. The current-voltage (I-V) characteristics of a fabricated nanocomposite sensor at a constant bias of $1.5 \mathrm{~V}$ measured in the range of 0 to $20 \mathrm{~mW} / \mathrm{cm}^{2} \mathrm{UV}$ illumination conditions are shown in Figure $5 b$. As the intensity of UV radiation increased, the current response of the device increased. Figure $5 \mathrm{c}$ represents the time-dependent stability of the sensor over a duration of $2.5 \mathrm{~h}$ under a dark and continuous illumination of $20 \mathrm{~mW} / \mathrm{cm}^{2} \mathrm{UV}$ radiation. Figure $5 \mathrm{c}$ 
shows that electric conductivity increased by over three orders of magnitude upon exposure of UV radiation. In addition, the results show the stability of the sensor over prolonged exposure time. The variation of the current with the change in the illuminated UV intensity at the constant bias of 1.5 voltage is presented in Figure $5 d$. According to Figure $5 d$, the linear relation $\left(R^{2}=0.987\right)$ was observed between the photocurrent and the intensity of UV radiation. The result demonstrates the wide dynamic range of the fabricated device. The current time characteristics of a fabricated pristine $\mathrm{ZnO}$ sensor at a constant bias of $1.5 \mathrm{~V}$ measured under periodic exposure of $20 \mathrm{~mW} / \mathrm{cm}^{2} \mathrm{UV}$ radiation is shown in Figure 5e. The composite material has demonstrated a $\sim 66 \%$ higher photocurrent response than $\mathrm{ZnO}$ alone (Figure 5a,e). The result shows the benefit of the composite material over the pristine metal oxide semiconductor. The current-voltage characteristics of a fabricated $\mathrm{ZnO}$ sensor measured under dark and $20 \mathrm{~mW} / \mathrm{cm}^{2} \mathrm{UV}$ illuminated conditions are shown in Figure $5 \mathrm{f}$.
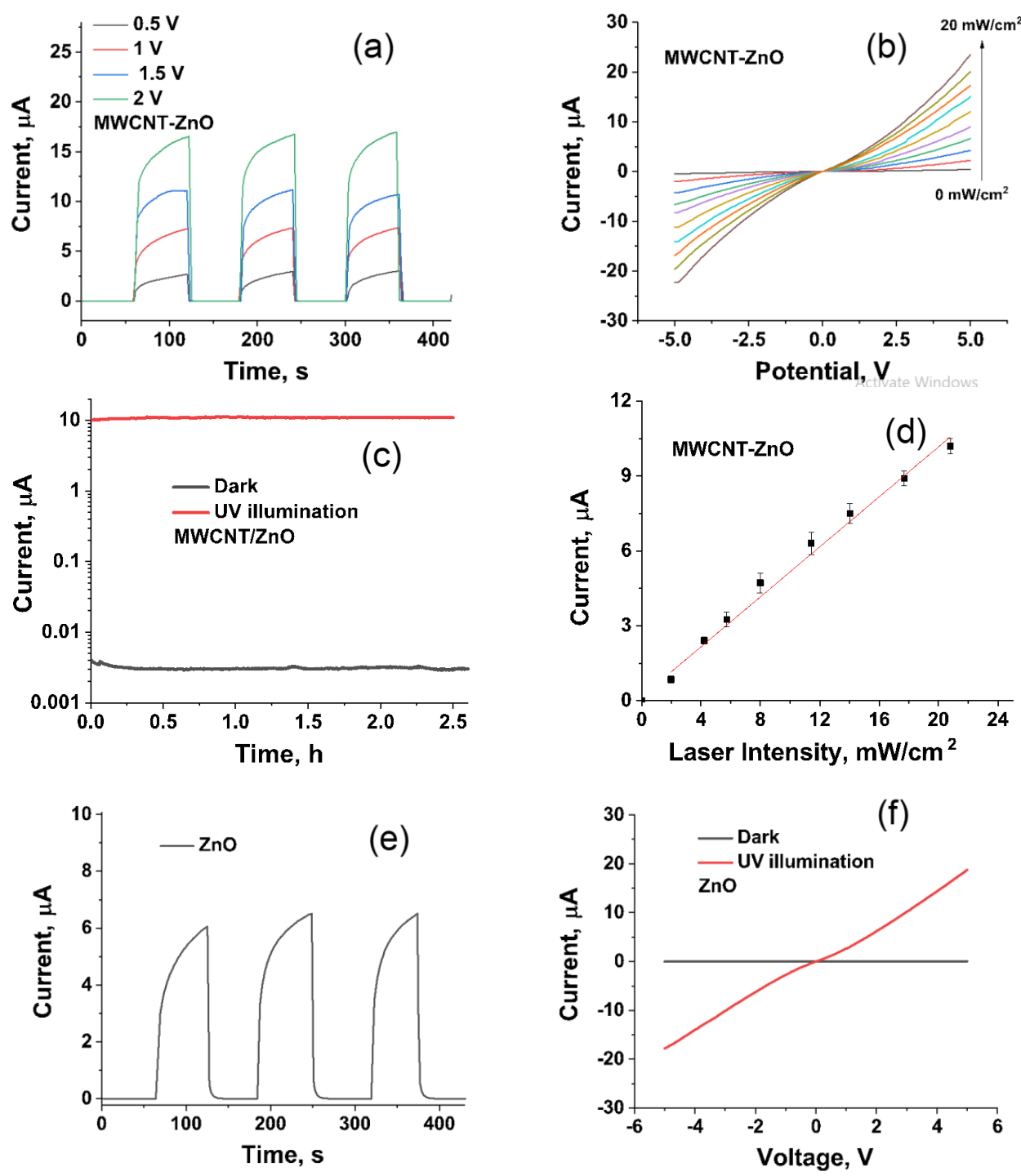

Figure 5. (a) Chronoamperometric responses of the OH-MWCNT/ZnO sensor towards cyclic exposure of $365 \mathrm{~nm}$ centered laser radiation at a bias voltage range of $0.5 \mathrm{~V}$ to $2 \mathrm{~V}$; (b) current-voltage (I-V) characteristics of a fabricated nanocomposite sensor at a constant bias of $1.5 \mathrm{~V}$ measured in the range of 0 to $20 \mathrm{~mW} / \mathrm{cm}^{2} \mathrm{UV}$ illumination; (c) the time-dependent stability of the sensor over a duration of $2.5 \mathrm{~h}$ under dark and continuous illumination of $20 \mathrm{~mW} / \mathrm{cm}^{2} \mathrm{UV}$ radiation; (d) the variation of the current with the change in the illuminated UV intensity at the constant bias of 1.5 voltage; (e) chronoamperometric responses of a pristine $\mathrm{ZnO}$ sensor towards a cyclic exposure of $20 \mathrm{~mW} / \mathrm{cm}^{2} \mathrm{UV}$ illumination at a constant bias of 1.5; and (f) current-voltage characteristics of a fabricated $\mathrm{ZnO}$ sensor. 
Responsivity measures the input-output gain of the sensor and is defined by the ratio of the photocurrent to the incident optical power of UV radiation [27]. Figure 6a shows the responsivity of the device with respect to change in the applied bias voltage. The responsivity increased with an increase in the bias voltage. The calculated value of the responsivity at an applied $5 \mathrm{~V}$ bias was $0.011 \mathrm{~A} / \mathrm{W}$. The photoresponse (ratio of current at UV illumination to dark) with respect to applied bias is presented in Figure $6 \mathrm{~b}$. The data shows the nearly linear relation between the photoresponse and the applied bias.
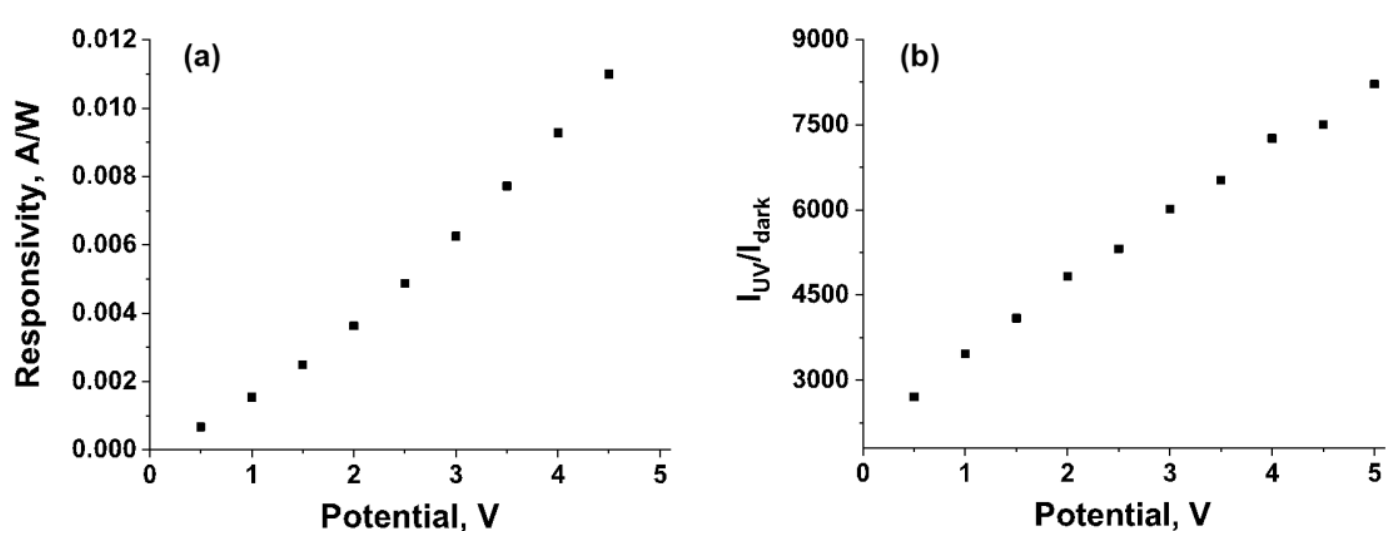

Figure 6. (a) Responsivity and (b) photoresponse $\left(\mathrm{I}_{\mathrm{UV}} / \mathrm{I}_{\mathrm{dark}}\right)$ of the device under $365 \mathrm{~nm}$ laser radiation.

The fabricated senor was compared with other previously reported sensors, as listed in Table 1 . The result clearly shows the fabricated sensor had a higher photoresponse $\left(\mathrm{I}_{\mathrm{UV}} / \mathrm{I}_{\mathrm{dark}}\right)$ value. The responsivity of the fabricated sensor could be further increased by increasing the amount of carbon nanotube content in the composite material, but decreased the photoresponse $\left(\mathrm{I}_{\mathrm{UV}} / \mathrm{I}_{\mathrm{dark}}\right)$ due to a significant increase in the dark current.

Table 1. Comparison of the fabricated sensor with the other reported sensors.

\begin{tabular}{cccccc}
\hline Material & Bias & $\begin{array}{c}\text { Responsivity, } \\
\mathbf{A} / \mathbf{W}\end{array}$ & $\mathbf{I}_{\mathbf{U V}} / \mathbf{I}_{\text {dark }}$ & Substrate & Ref. \\
\hline Carbon/ZnO & $1 \mathrm{~V}$ & 0.38 & $<10$ & Rigid & {$[17]$} \\
MWCNT/ZnO & $5 \mathrm{~V}$ & - & 2.68 & Rigid & {$[18]$} \\
CNT/ZnO & $2 \mathrm{~V}$ & 2.1 & 34 & Rigid & {$[19]$} \\
MWCNT/ZnO & $10 \mathrm{~V}$ & $4.8 \times 10^{-4}$ & $7.3 \times 10^{3}$ & Rigid & {$[20]$} \\
OH-MWCNT/ZnO & $5 \mathrm{~V}$ & 0.011 & $8.2 \times 10^{4}$ & Flexible & This work \\
\hline
\end{tabular}

\subsection{Response of Device under Solar Radiation}

To demonstrate the real-life application of the device, the flexible fabricated composite sensor was tested under solar radiation. Figure 7a shows a cyclic UV response of the sensor, and Figure $7 \mathrm{~b}$ shows an I-V characteristic of the device under solar radiation and the dark current radiation. This shows the potential application of the device as a real-time wearable UV sensor. The solar UV intensity was calculated using a linear equation obtained from Figure $5 \mathrm{~d}$ was $\sim 2.1 \mathrm{~mW} / \mathrm{cm}^{2}$. The typical UV intensity of solar radiation ( 280 to $400 \mathrm{~nm}$ ) is 2 to $5 \mathrm{~mW} / \mathrm{cm}^{2}$ [28]. 

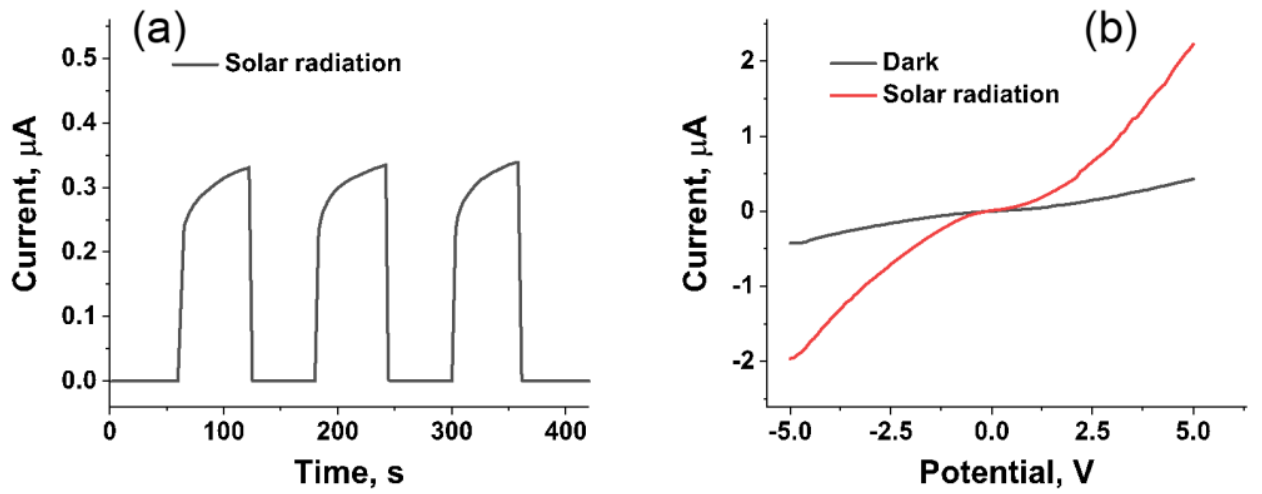

Figure 7. (a) Chronoamperometric response of the composite sensor towards cyclic exposure of solar radiation at a bias voltage of $1.5 \mathrm{~V}$; and (b) IV characteristics of the device.

\section{Conclusions}

A flexible, wearable, and visible-blind nanocomposite UV sensor was fabricated on a PET substrate using a screen-printing method. The robust performance of the UV sensor was attributed to the collective and synergetic performance of carbon nanotube as a conductive node and the $\mathrm{ZnO}$ as a sensing node in the composite material. In addition, the use of functionalized carbon nanotube enhanced the interconnection between the carbon nanotube and metal oxide semiconductors. The photoresponses were observed under static and periodic UV radiation conditions, which demonstrated the reliability and repeatability of the proposed sensor. The fabricated sensor was also evaluated under solar UV radiation to demonstrate the applicability of the sensor for real-time monitoring of UV radiation for environmental safety and human healthcare.

Author Contributions: H.J.C. and P.P. conceived and designed the experiments. P.P. and S.P. performed the experiments and analyzed the data. P.P and H.J.C. wrote the manuscript. H.J.C. supervised the project. All authors have read and agreed to the published version of the manuscript.

Funding: This work was supported in part by the NSF I/UCRC on Multi-functional Integrated System Technology (MIST) Center IIP-1439644, IIP-1439680, and IIP-1738752, and also by the Ministry of Trade, Industry and Energy (MOTIE) and Korea Institute for Advancement of Technology(KIAT) through the International Cooperative R\&D program (P0006858).

Conflicts of Interest: The authors declare no conflict of interest.

\section{References}

1. Moan, J. Ozone holes and biological consequences. J. Photochem. Photobiol. B Biol. 1991, 9, 244-247. [CrossRef]

2. Henriksen, T.; Dahlback, A.; Larsen, S.H.; Moan, J. Ultraviolet-radiation and skin cancer. Effect of an ozone layer depletion. Photochem. Photobiol. 1990, 51, 579-582. [CrossRef] [PubMed]

3. Brash, D.E.; Rudolph, J.A.; Simon, J.A.; Lin, A.; McKenna, G.J.; Baden, H.P.; Halperin, A.J.; Ponten, J. A role for sunlight in skin cancer: UV-induced p53 mutations in squamous cell carcinoma. Proc. Natl. Acad. Sci. USA 1991, 88, 10124-10128. [CrossRef] [PubMed]

4. Wang, X.; Cho, H.J. p-CuO nanowire/n-ZnO nanosheet heterojunction-based near-uv sensor fabricated by electroplating and thermal oxidation process. Mater. Lett. 2018, 223, 170-173. [CrossRef]

5. Chen, Y.-C.; Lu, Y.-J.; Lin, C.-N.; Tian, Y.-Z.; Gao, C.-J.; Dong, L.; Shan, C.-X. Self-powered diamond $/ \beta_{-}-\mathrm{Ga}_{2} \mathrm{O}_{3}$ photodetectors for solar-blind imaging. J. Mater. Chem. C 2018, 6, 5727-5732. [CrossRef]

6. Yang, D.; Ma, D. Development of organic semiconductor photodetectors: From mechanism to applications. Adv. Opt. Mater. 2019, 7, 1800522. [CrossRef]

7. Pathak, P.; Podzorski, M.; Bahnemann, D.; Subramanian, V.R. One-Pot Fabrication of High Coverage PbS Quantum Dot Nanocrystal-Sensitized Titania Nanotubes for Photoelectrochemical Processes. J. Phys. Chem. C 2018, 122, 13659-13668. [CrossRef] 
8. Bamshad, A.; Cho, H.J. Digital Microfabrication on Paper and Cloth for Heavy Metal Detection and Remediation. In Proceedings of the 2019 20th International Conference on Solid-State Sensors, Actuators and Microsystems \& Eurosensors XXXIII (TRANSDUCERS \& EUROSENSORS XXXIII), Berlin, Germany, 23-27 June 2019; pp. 685-688.

9. Pathak, P.; Gupta, S.; Grosulak, K.; Imahori, H.; Subramanian, V. Nature-inspired tree-like $\mathrm{TiO}_{2}$ architecture: A 3D platform for the assembly of CdS and reduced graphene oxide for photoelectrochemical processes. J. Phys. Chem. C 2015, 119, 7543-7553. [CrossRef]

10. Sun, Y.-F.; Liu, S.-B.; Meng, F.-L.; Liu, J.-Y.; Jin, Z.; Kong, L.-T.; Liu, J.-H. Metal oxide nanostructures and their gas sensing properties: A review. Sensors 2012, 12, 2610-2631. [CrossRef]

11. Zhai, T.; Fang, X.; Liao, M.; Xu, X.; Zeng, H.; Yoshio, B.; Golberg, D. A comprehensive review of one-dimensional metal-oxide nanostructure photodetectors. Sensors 2009, 9, 6504-6529. [CrossRef]

12. Xu, Q.; Cheng, L.; Meng, L.; Wang, Z.; Bai, S.; Tian, X.; Jia, X.; Qin, Y. Flexible Self-Powered ZnO Film UV Sensor with a High Response. ACS Appl. Mater. Interfaces 2019, 11, 26127-26133. [CrossRef] [PubMed]

13. Pathak, P.; Israel, L.H.; Pereira, E.J.M.; Subramanian, V.R. Effects of carbon allotrope interface on the photoactivity of rutile one-dimensional (1D) $\mathrm{TiO}_{2}$ coated with anatase $\mathrm{TiO}_{2}$ and sensitized with CdS nanocrystals. ACS Appl. Mater. Interfaces 2016, 8, 13400-13409. [CrossRef] [PubMed]

14. Chen, T.; Wang, S.; Yang, Z.; Feng, Q.; Sun, X.; Li, L.; Wang, Z.S.; Peng, H. Flexible, light-weight, ultrastrong, and semiconductive carbon nanotube fibers for a highly efficient solar cell. Angew. Chem. Int. Ed. 2011, 50, 1815-1819. [CrossRef] [PubMed]

15. Hirsch, A. The era of carbon allotropes. Nat. Mater. 2010, 9, 868-871. [CrossRef] [PubMed]

16. Kongkanand, A.; Martínez Domínguez, R.; Kamat, P.V. Single wall carbon nanotube scaffolds for photoelectrochemical solar cells. Capture and transport of photogenerated electrons. Nano Lett. 2007, 7, 676-680. [CrossRef]

17. Wang, R.-C.; Hsu, C.-C.; Chen, S.-J. The evolution of well-aligned amorphous carbon nanotubes and porous $\mathrm{ZnO} / \mathrm{C}$ core-shell nanorod arrays for photosensor applications. Nanotechnology 2010, 22, 035704. [CrossRef]

18. Boruah, B.D.; Misra, A. Conjugated assembly of colloidal zinc oxide quantum dots and multiwalled carbon nanotubes for an excellent photosensitive ultraviolet photodetector. Nanotechnology 2016, 27, 355204. [CrossRef]

19. Safa, S. Enhanced UV-detection properties of carbon nanotube impregnated ZnO nanourchins. Opt. Int. J. Light Electron Opt. 2015, 126, 2194-2198. [CrossRef]

20. Lupan, O.; Schütt, F.; Postica, V.; Smazna, D.; Mishra, Y.K.; Adelung, R. Sensing performances of pure and hybridized carbon nanotubes-ZnO nanowire networks: A detailed study. Sci. Rep. 2017, 7, 1-12. [CrossRef]

21. Yi, P.; Chen, K.L. Influence of surface oxidation on the aggregation and deposition kinetics of multiwalled carbon nanotubes in monovalent and divalent electrolytes. Langmuir 2011, 27, 3588-3599. [CrossRef]

22. Al Abdullah, K.; Awad, S.; Zaraket, J.; Salame, C. Synthesis of ZnO nanopowders by using sol-gel and studying their structural and electrical properties at different temperature. Energy Procedia 2017, 119, 565-570. [CrossRef]

23. Ma, P.C.; Tang, B.Z.; Kim, J.-K. Effect of CNT decoration with silver nanoparticles on electrical conductivity of CNT-polymer composites. Carbon 2008, 46, 1497-1505. [CrossRef]

24. Li, S.-S.; Su, Y.-K. Improvement of the performance in Cr-doped $\mathrm{ZnO}$ memory devices via control of oxygen defects. RSC Adv. 2019, 9, 2941-2947. [CrossRef]

25. Gong, P.; Wang, J.; Sun, W.; Wu, D.; Wang, Z.; Fan, Z.; Wang, H.; Han, X.; Yang, S. Tunable photoluminescence and spectrum split from fluorinated to hydroxylated graphene. Nanoscale 2014, 6, 3316-3324. [CrossRef]

26. Lee, S.W.; Yabuuchi, N.; Gallant, B.M.; Chen, S.; Kim, B.-S.; Hammond, P.T.; Shao-Horn, Y. High-power lithium batteries from functionalized carbon-nanotube electrodes. Nat. Nanotechnol. 2010, 5, 531. [CrossRef]

27. Guo, L.; Zhang, H.; Zhao, D.; Li, B.; Zhang, Z.; Jiang, M.; Shen, D. High responsivity ZnO nanowires based UV detector fabricated by the dielectrophoresis method. Sens. Actuators B Chem. 2012, 166, 12-16. [CrossRef]

28. El Ghissassi, F.; Baan, R.; Straif, K.; Grosse, Y.; Secretan, B.; Bouvard, V.; Benbrahim-Tallaa, L.; Guha, N.; Freeman, C.; Galichet, L. A review of human carcinogens-Part D: Radiation. Lancet Oncol. 2009, 10, 751-752. [CrossRef]

(C) 2020 by the authors. Licensee MDPI, Basel, Switzerland. This article is an open access article distributed under the terms and conditions of the Creative Commons Attribution (CC BY) license (http://creativecommons.org/licenses/by/4.0/). 